\title{
ENCAPSULATION OF PARTIALLY PURIFIED BROMELAIN FROM PINEAPPLE CORES IN ALGINATE-PECTIN BEADS AS A TARGETED ANTIPLATELET AGENT
}

\author{
HEGI ADI PRABOWO, EMIL BUDIANTO, SUMI HUDIYONO*
}

Department of Chemistry, Faculty of Mathematics and Natural Sciences, Universitas Indonesia, Depok 16424, West Java, Indonesia *Email: sumi.hudiyono@sci.ui.ac.id

Received: 19 Feb 2021, Revised and Accepted: 06 Apr 2021

ABSTRACT

Objective: Oral administration of bromelain can decrease its bioactivity once it makes contact with stomach acid. Therefore, bromelain was loaded into alginate (Alg), pectin (Pec), and alginate-pectin (AP) beads to control its release into the intestines and avoid degradation.

Methods: Crude bromelain was purified by ammonium sulfate precipitation and the dialysis process. In vitro releases and kinetics studies of bromelain-loaded alginate-pectin beads were carried out using an acid and phosphate buffer medium. The beads were characterized using physical analysis, Fourier-Transform Infrared Spectroscopy (FTIR) analysis, and Differential Scanning Calorimetry (DSC) analysis.

Results: The dialysis fraction of bromelain has a specific activity of $67.93 \mathrm{U} / \mathrm{mg}, 3.05$ times that of crude bromelain. That fraction was encapsulated in Alg, Pec, and AP beads with a range of encapsulation efficiency around $82.70-91.39 \%$. Bromelain-loaded pectin and AP19 beads were chosen to study in an in vitro release based on their swelling properties and encapsulation efficiency. Bromelain-loaded AP19 beads have lower release than bromelain-loaded pectin beads in both dissolution mediums. The cumulative releases of AP19 are 9.99 and $87.81 \%$ in $0.1 \mathrm{~N}$ HCl and phosphate buffer medium, respectively. Bromelain-loaded P and AP beads both follow the zero-order kinetics model and the dissolution mechanism of the beads is non-Fickian with a combination of diffusion and erosion. The in vitro antiplatelet activity of dissolution aliquots (20.51 and $18.48 \%$ ) is lower than its dialysis fraction (56.04\%).

Conclusion: This in vitro research data shows promising potency for AP as a carrier for oral administration of bromelain as an antiplatelet agent.

Keywords: Bromelain, Alginate-pectin, In vitro release, Kinetics

(C) 2021 The Authors. Published by Innovare Academic Sciences Pvt Ltd. This is an open access article under the CC BY license (https://creativecommons.org/licenses/by/4.0/) DOI: https://dx.doi.org/10.22159/ijap.2021v13i3.41158. Journal homepage: https://innovareacademics.in/journals/index.php/ijap

\section{INTRODUCTION}

Cardiovascular disease (CVD) is the most widely recognized cause of death for people of all ages. It caused 17.9 million deaths in 2016, representing $31 \%$ of all global deaths. Heart attack and stroke take about $85 \%$ of these deaths [1]. Cerebrovascular strokes and cardiovascular attacks can be triggered by the rupture of vulnerable plaques in atherosclerosis and thrombotic processes [2, 3]. The fundamental processes in the development of atherothrombosis are inflammation and thrombosis which platelets act as a bridge in those processes [2, 4]. In general, the pathogenies of thrombus formation are platelet activation, subsequent adhesion, the release of granule content, and platelet aggregation $[2,5]$. The multiple mechanisms and side effects of commercial drugs make the researcher thought that natural bioactive compounds are very useful to prevent or complementary antiplatelet therapy.

One natural product with therapeutic advantages is bromelain. Bromelain is a proteolytic enzyme contained in pineapple plants and can act as an anticoagulant, antibiotic, anti-inflammatory, and antiplatelet [6]. Oral consumption of bromelain can reduce its biological activity due to contact with gastric fluids that have low acidity. In the in vitro study, bromelain activity significantly reduced in the artificial gastric fluid after the first four hours [7, 8], while bromelain can absorb into the intestine without losing its biological activity [9]. Hence, the bromelain must be encapsulated to prevent it from making contact with gastric fluid in the GI tract.

Natural biopolymers are a commonly used compound in intestina drug delivery systems. One of these is a polysaccharide that has $\mathrm{pH}$ responsive properties. The formation of a polyelectrolyte complex between alginate and pectin is an interesting thing to develop as a drug carrier. Complex forming of alginate-pectin with a simple calcium ion gelation method has been reported as an intestinal drug delivery system due to its $\mathrm{pH}$-dependent properties [10]. The combinations of alginate-pectin show stability as carriers due to strong synergic effects in acidic conditions, which increase its encapsulation efficiency [11]. Therefore, alginate-pectin beads are used as the bromelain carrier in this research. In vitro dissolution of bromelain isolated from pineapple cores loaded alginate-pectin beads was evaluated in $0.1 \mathrm{~N} \mathrm{HCl}$ and buffer phosphate $\mathrm{pH} 6.8$ medium. The kinetics and antiplatelet activity of the dissolution aliquots obtained were studied.

\section{MATERIALS AND METHODS}

\section{Materials}

The bromelain source in this experiment was isolated from pineapple that was purchased from a traditional market in Jakarta. Sodium alginate was purchased from the Kimica Corporation, pectin from CPKelco, commercial bromelain and ADP from Sigma, and the other chemicals were bought from Merck.

Isolation, ammonium sulfate precipitation, and dialysis of bromelain

The isolation, ammonium sulfate precipitation, and dialysis of bromelain from the pineapple cores were conducted by the previously mentioned method with slight modifications [7]. The precipitation process was changed; ammonium sulfate precipitation was used at a concentration of $60 \%$, and centrifugation speed was increased to $8000 \mathrm{rpm}$.

\section{Determination of specific activities}

Specific activities of bromelain were determined by dividing total proteolytic activity (U) with total protein contents (mg). The proteolytic activities were determined according to the Kunitz method with modification on phosphate buffer ( $\mathrm{pH} 7$ ) and temperature incubation of $50{ }^{\circ} \mathrm{C}$ [12]. While the total protein contents were measured using UV-Vis spectrophotometry at $750 \mathrm{~nm}$ using the Lowry method [13].

Synthesis of crosslinked alginate (Alg), pectin (Pec), and alginate-pectin (AP) beads

Sodium alginate or pectin beads were synthesized by mixing biopolymer powder (table 2) with $100 \mathrm{ml}$ of fresh distilled water. 
The mixture was stirred at $400 \mathrm{rpm}$ until homogenous and sonicated (Alstron, ALD-40050-18H) at $40 \mathrm{kHz}$ for $15 \mathrm{~min}$ to remove air bubbles. The homogenous solution was dropped into $100 \mathrm{ml}$ calcium chloride solution (5\%) using a $24 \mathrm{G}$ syringe needle Terumo. The alginate beads were continuously stirred for $30 \mathrm{~min}$ to produce stable beads. The beads were collected and washed twice with distilled water to remove excess calcium chloride from their surfaces. The obtained beads were air-dried for around $24 \mathrm{~h}$. The alginate-pectin beads were synthesized by mixing various formulas of alginate and pectin into $100 \mathrm{ml}$ of distilled water (table 2). The AP beads were prepared using the ionotropic gelation method as mentioned above. Bromelain-loaded hydrogel beads were conducted by addition $100 \mathrm{mg}$ of bromelain obtained from isolation to the mixture before the ionotropic gelation process.

Determination of beads size, density, and morphological surface analysis

The bead's size was measured using a stereomicroscope (Boeco, Germany). The size of 100 beads was randomly selected for each formula and then the results reported as meantstandard deviation. The determination of bead density was conducted by dividing a bead's mass by its volume. The morphological characterization of the beads was conducted using scanning electron microscopy (SEM) (EVO 50, ZEISS, UK), and the images were captured at various magnifications.

\section{Fourier-transform infrared spectroscopy (FTIR) characterization}

Each powder of sample beads was mixed with potassium bromide $(\mathrm{KBr})$ at a ratio of 1:9 and ground until homogeny was reached. The sample was placed into a sample holder, and the spectral was taken at a range of $4000-400 \mathrm{~cm}^{-1}$ with a resolution of $2 \mathrm{~cm}^{-1}$ using FTIR spectroscopy (Shimadzu IRPrestige-21).

\section{Differential scanning calorimetry (DSC)}

DSC of beads was performed by DSC-60A (Shimadzu). The sample was weighed $25 \mathrm{mg}$ and scanned in an aluminum pan over a temperature range of between 50 and $350{ }^{\circ} \mathrm{C}$ at a scan rate of 10 ${ }^{\circ} \mathrm{C} / \mathrm{min}$ in the air atmosphere.

\section{Determination of swelling ratio of the beads}

The swelling ratio study was conducted by weighing a mass of dry beads $\left(m_{d}\right)$ and then soaking it in different solutions; there are $0.1 \mathrm{~N}$ $\mathrm{HCl}$ and phosphate buffer $\mathrm{pH} 6.8$ for $30 \mathrm{~min}$ at room temperature. Excess water on the hydrogel beads' surface was removed using filter paper and then weighed $\left(\mathrm{m}_{\mathrm{w}}\right)$. The swelling ratio was calculated using the following equation [14].

$$
\% \text { Swelling ratio }=\frac{m_{w}-m_{d}}{m_{d}} \times 100 \%
$$

\section{Determination of encapsulation efficiency}

$100 \mathrm{mg}$ of each type of bromelain-loaded hydrogel beads was crushed. The crushed beads were soaked in $100 \mathrm{ml}$ of phosphate buffer ( $\mathrm{pH}$ 7.4), kept overnight, which was followed by $15 \mathrm{~min}$ of sonication. The remaining debris in the solution was removed using filtering paper [14]. The bromelain content was measured by using a spectrophotometer at $280 \mathrm{~nm}$ with BSA solution as a standard. The efficiency of encapsulation of bromelain was calculated using the following equation [15].

$$
\begin{gathered}
\text { The efficiency of encapsulation }=\frac{\text { Actual bromelain content in beads }}{\text { Theoretical bromelain content in beads }} \times \\
100 \%
\end{gathered}
$$

\section{In vitro dissolution and its kinetics study}

The in vitro dissolution of beads was carried out using a USP dissolution apparatus, I-Basket type (Electolab TDT-08L). The condition of the dissolution was at temperature $37 \pm 0.5^{\circ} \mathrm{C}$ under 100 rpm speed. Bromelain-loaded beads were weighing one gram and put into the basket. The basket was immersed into $750 \mathrm{ml}$ of $0.1 \mathrm{~N}$ $\mathrm{HCl}$ for $2 \mathrm{~h}$, and then $250 \mathrm{ml}$ of $0.2 \mathrm{M}$ sodium phosphate tribasic was added into the system and continuously stirred for $45 \mathrm{~min}$. The amount of $10 \mathrm{ml}$ of aliquots was taken at regular time intervals, and the same amount of fresh medium was added into the system. The obtained aliquots were filtered and the absorbance measured using UV-Vis spectrophotometry (Shimadzu UV-2450) at $280 \mathrm{~nm}$ with BSA solutions as a standard [15]. The in vitro dissolution data was analyzed using various kinetic equations, such as zero-order, firstorder, Higuchi, and Korsmeyer-Peppas. The correlation coefficient $\left(\mathrm{R}^{2}\right)$ and constant $(\mathrm{k})$ values were obtained from regression analysis of linear curve plotting while the release mechanism was determined by the diffusion exponent ' $n$ ', which was obtained from the Korsmeyer-Peppas plot of initial $60 \%$ of the cumulative release of bromelain [14].

\section{In vitro antiplatelet activity}

The determination of antiplatelet activity was conducted by mixing $70 \mu \mathrm{l}$ of the sample, $560 \mu \mathrm{l}$ of platelet-rich plasma (PRP), and $3.3 \mathrm{ml}$ of saline solution. The mixture was shaken using a vortex and then incubated for $10 \mathrm{~min}$ at $37^{\circ} \mathrm{C}$; absorbance was measured using UVVis spectrophotometry at $600 \mathrm{~nm}$ (A $A_{\text {before}}$ ). Next, to trigger the aggregation of PRP, $70 \mu \mathrm{l}$ ADP $5 \mu \mathrm{M}$ was added into the mixture, which was incubated for $10 \mathrm{~min}$ at $37^{\circ} \mathrm{C}$. The absorbance of the final mixture was measured using UV-Vis spectrophotometry at $600 \mathrm{~nm}$ $\left(A_{\text {after }}\right)$. In this step, water was used as a negative control (NC), while cilostazol and aspirin $(1 \mathrm{mg} / \mathrm{ml})$ used as positive controls (PC). The percentages of platelet aggregation and antiplatelet activity were calculated using the following formula [12]:

$$
\begin{gathered}
\text { Percentage of platelet aggregation }=\left(1-\frac{\mathrm{A}_{\mathrm{after}}}{\mathrm{A}_{\mathrm{bef}} \mathrm{re}}\right) \times 100 \% \\
\text { Percentage of antiplatelet activity }= \\
\frac{\text { \%ggregation of negative control }-\% \text { Aggregation of sample }}{\text { \%Agreagation of negative control }} \times 100 \%
\end{gathered}
$$

\section{RESULTS AND DISCUSSION}

Isolation, ammonium sulfate precipitation, and dialysis of bromelain

The isolation process was carried out via the centrifugation of pineapple cores juice at $8000 \mathrm{rpm}$ in temperature conditions of $\pm 4{ }^{\circ} \mathrm{C}$ for $15 \mathrm{~min}$. This process aims to separate crude bromelain solution from other solid pineapple fibers. In order to concentrate the protein, ammonium sulfate precipitation with a final saturation of $60 \%$ was added to the crude bromelain solution. The precipitation of protein occurred during the salting-out process. At that ammonium salt saturation level, protein-

\begin{tabular}{|c|c|c|c|c|c|c|}
\hline \multirow[t]{2}{*}{ Sample } & \multicolumn{2}{|l|}{ Average of total } & \multirow{2}{*}{$\begin{array}{l}\text { Specific activity* } \\
\text { (U/mg) }\end{array}$} & \multirow{2}{*}{$\begin{array}{l}\text { Purification } \\
\text { levels (fold) }\end{array}$} & \multirow{2}{*}{$\begin{array}{l}\text { Yield } \\
(\%)\end{array}$} & \multirow[t]{2}{*}{ Recovery (\%) } \\
\hline & Proteolytic activity (U) & Protein (mg) & & & & \\
\hline Crude bromelain (CB) & 208355.70 & 9387.00 & $22.20 \pm 0.11$ & 1.00 & 100 & 100 \\
\hline $\begin{array}{l}\text { Ammonium sulfate } 60 \% \\
\text { fraction (F60) }\end{array}$ & 29966.44 & 632.63 & $47.37 \pm 0.11$ & 2.12 & 14.32 & 6.74 \\
\hline Dialysis fraction (DF) & 36434.00 & 536.35 & $67.93 \pm 0.21$ & 3.05 & 17.41 & 5.71 \\
\hline Remaining fraction (RF) & 62416.11 & 7927.50 & $7.87 \pm 0.17$ & 0.35 & 29.18 & 84.45 \\
\hline
\end{tabular}
protein interactions will be stronger than protein-solvent interactions, which trigger protein molecules to make an aggregate with lower solubility. The bromelain aggregate can be separated from the solution with centrifugation in the same condition as above.

Table 1: The specific activity of bromelain in each purification step

*Data represented as mean $\pm \mathrm{SD}(\mathrm{n}=3)$ 
This process increases the protein levels in bromelain, which is in line with its proteolytic activity. The ammonium sulfate in bromelain was removed by dialysis using a membrane with $14 \mathrm{kDa}$ pores which smaller than bromelain molecules (23-36 kDa) [16]. The difference in the concentration of phosphate buffer of the dialysis system and bromelain causes the diffusion process to occur. The ammonium sulfate and small proteins in bromelain will move through the dialysis membrane into the phosphate buffer with a lower concentration. The dialysis process will stop when the concentration of phosphate buffer reaches equilibrium. This process will decrease the protein content level and increase the proteolytic activity of the bromelain. The specific activity data of the bromelain is shown in table 1. As shown in the FTIR spectrum in fig. 1, bromelain has $\mathrm{OH}$ and $\mathrm{NH}$ overlapping bands at $3700-3000 \mathrm{~cm}^{-1}$. A peak of $1660 \mathrm{~cm}^{-1}$ indicates a strong intensity of $\mathrm{C}=0$ stretch (amide I area), and a C-N stretch band appears at $1546 \mathrm{~cm}^{-1}$ [17].

Synthesis of bromelain loaded-alginate (Alg), pectin (Pec), alginate-pectin (AP) beads

Beads were formed by dropping alginate, pectin, or alginate-pectin solution into calcium chloride solution. The presence of the $\mathrm{Ca}^{2+}$ ion triggers an ionic crosslink between the anionic guluronic unit in the alginate and the galacturonic unit in the pectin to form an egg box conformation. Various divalent ions can lead to an egg box confirmation with an anionic biopolymer such as $\mathrm{Pb}^{2+}, \mathrm{Cu}^{2+}, \mathrm{Ba}^{2+}$, and $\mathrm{Sr}^{2+}$. The calcium ion was used in this research because it does not inhibit bromelain activity. The FTIR spectra of sodium alginate, pectin, placebo alginate-pectin, and bromelain-loaded alginate-pectin with $\mathrm{KBr}$ were taken at wavenumber $4000-400 \mathrm{~cm}^{-1}$ and resolution $2 \mathrm{~cm}^{-1}$. Fig. 1 shows some characteristic bands elucidating interaction and fingerprint for biopolymers. Overall, there are five regions proposed in the spectrum, at ranges $3800-3000 \mathrm{~cm}^{-1}$ (O-H stretching), 3000-2500 $\mathrm{cm}^{-1}$ (aliphatic stretching), 1800-1390 $\mathrm{cm}^{-1}$ (C-O stretching), 1250$800 \mathrm{~cm}^{-1}$ (fingerprint region for polysaccharide), and under $800 \mathrm{~cm}^{-1}$ (not considered for polysaccharides).
In the first region, the absorption at $3800-3000 \mathrm{~cm}^{-1}$ can be seen as a vibration of $\mathrm{O}-\mathrm{H}$ stretching from $\beta$-D-mannuronic acid and $\alpha$-L(1-4)-guluronic acid in sodium alginate. The strong vibration stretch of $\mathrm{O}-\mathrm{H}$ from pectin for intermolecular and intramolecular of a hydrogen bond from $\alpha$-D-galacturonic acid appears at 3700-3000 $\mathrm{cm}^{-1}$. During the blending process, the vibrational mode of these polymers shifted slightly towards the lower wavenumber due to this intermolecular hydrogen bonding. Thermodynamically, this intermolecular interaction was favored due to the free energy of the molecules combined with the alginate-pectin as compared to its individual polymer [18]. The interaction between alginate and pectin causes a slight shifting of the aliphatic band from $2941 \mathrm{~cm}^{-1}$ in pectin to $2946 \mathrm{~cm}^{-1}$. The FTIR spectra of carbonyl ester $\left(\mathrm{COCH}_{3}\right)$ and the asymmetric stretching in the carboxylic ion ( $\left.\mathrm{COO}^{-}\right)$in pectin appear at 1740 and $1673 \mathrm{~cm}^{-1}$ [19], while the symmetric stretches of carboxylic and scissors vibration of acetyl and methoxy groups appear at 1435 and $1344 \mathrm{~cm}^{-1}$.

At the sodium alginate spectrum, bands at 1600 and $1414 \mathrm{~cm}^{-1}$ from CO stretching due to asymmetric and symmetric COO-ion, respectively. In fig. 1 , the stretching vibration of the esterified carboxyl in pectin at $1740 \mathrm{~cm}^{-1}$ disappears in the AP beads. The deesterification of the ester carbonyl group forms stable hydrogen bonds between the $\mathrm{OH}$ group, the $\mathrm{COO}$-ion, and the $\mathrm{Na}^{+}$or $\mathrm{Ca}^{2+}$ ion to create the egg-box structure [20]. The de-esterification process also proves by the disappearance band of pectin at $1210 \mathrm{~cm}^{-1}$ in AP refers to $\mathrm{CO}$ asymmetric stretch. The increasing intensity and sharpness of the AP band at $1614 \mathrm{~cm}^{-1}$ indicates a stronger hydrogen bond between the polymers. A new band appears in the AP spectrum that is the symmetric stretching of $\mathrm{CO}$ because of the $\mathrm{COO}$ ion at wavenumber 1436 and $1337 \mathrm{~cm}^{-1}$. This stretching vibration is absent in individual polymers and proves that new COO groups form after the de-esterification process. There is a band at $1250-1050 \mathrm{~cm}^{-}$ 1 for the $\mathrm{C}-\mathrm{O}-\mathrm{C}$ stretch related to the glycoside bond of the biopolymer for the entire spectrum [18].

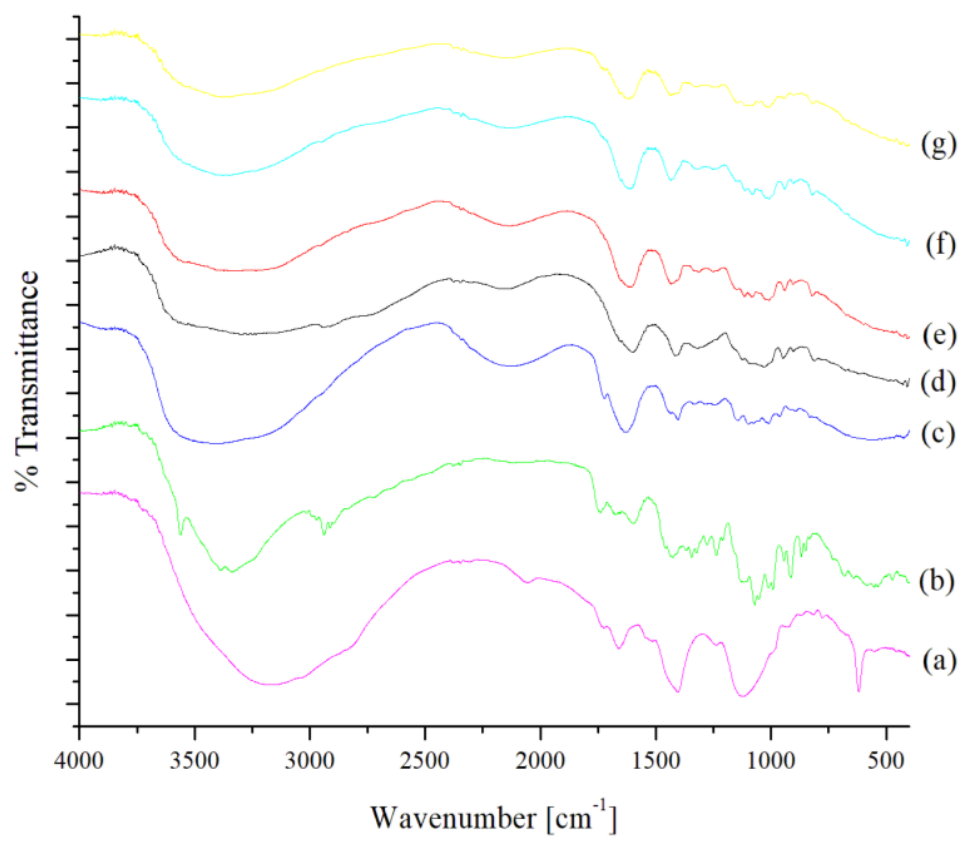

Fig. 1: FTIR spectra of a) bromelain, b) pectin, c) bromelain-loaded pectin, d) alginate, e) bromelain-loaded alginate, f) alginate-pectin, g) bromelain-loaded alginate-pectin

\section{Beads size, density, morphological surface analysis}

Uniformity, density, and sphericality of the bead size play crucial roles in drug release behavior in the GI tract. The composition of the polymer affects the bead size and density. Based on table 2, individual pectin beads are the smallest in size and density, followed by alginate beads. The AP beads with higher amounts of pectin are also bigger. The density of the beads decreases as the number of pectin increases. As seen in the morphological analysis in fig. 2, alginate has a spherical form while pectin and AP have little tails on the tips of the spheres that are created through the dropping of the polymer solution into the calcium chloride solution. The surfaces of those beads are very rough, which affects the strength of the beads in the dissolution medium. 
Table 2: Bead size, density, and encapsulation efficiency of bromelain

\begin{tabular}{|c|c|c|c|c|c|c|}
\hline \multirow[t]{2}{*}{ Beads } & \multicolumn{2}{|c|}{ Ratios } & \multirow[t]{2}{*}{$\mathrm{CaCl}_{2}(\%)$} & \multirow[t]{2}{*}{ Bead size $^{*_{a}}(\mu \mathrm{m})$} & \multirow[t]{2}{*}{${\text { Density*b }\left(\mathrm{g} / \mathrm{cm}^{3}\right)}^{3}$} & \multirow{2}{*}{$\begin{array}{l}\text { Encapsulation efficiency*c } \\
(\%)\end{array}$} \\
\hline & Alg & Pec & & & & \\
\hline Alg & 3 & 0 & 5 & $1031.51 \pm 38.53$ & $1.31 \pm 0.05$ & $82.70 \pm 0.54$ \\
\hline Pec & 5 & 0 & 5 & $963.99 \pm 76.13$ & $1.05 \pm 0.03$ & $91.39 \pm 1.86$ \\
\hline AP 91 & 9 & 1 & 5 & $1167.81 \pm 82.36$ & $1.28 \pm 0.09$ & $83.10 \pm 0.72$ \\
\hline AP 51 & 5 & 1 & 5 & $1176.48 \pm 70.49$ & $1.22 \pm 0.06$ & $84.05 \pm 0.73$ \\
\hline AP 21 & 2 & 1 & 5 & $1279.46 \pm 90.61$ & $1.18 \pm 0.03$ & $86.31 \pm 2.00$ \\
\hline AP 11 & 1 & 1 & 5 & $1298.67 \pm 87.90$ & $1.16 \pm 0.07$ & $87.00 \pm 1.01$ \\
\hline AP 12 & 1 & 2 & 5 & $1304.17 \pm 78.56$ & $1.13 \pm 0.05$ & $88.60 \pm 1.19$ \\
\hline AP 15 & 1 & 5 & 5 & $1320.54 \pm 92.02$ & $1.09 \pm 0.08$ & $88.78 \pm 1.11$ \\
\hline AP 19 & 1 & 9 & 5 & $1379.00 \pm 107.84$ & $1.08 \pm 0.06$ & $90.07 \pm 0.56$ \\
\hline \multicolumn{7}{|c|}{ Alg, AP91-AP21: Total concentration of polymer 3\% (w/v) } \\
\hline \multicolumn{7}{|c|}{ Pec, AP11-AP19: Total concentration of polymer $5 \%(\mathrm{w} / \mathrm{v})$} \\
\hline
\end{tabular}

*Data represented as mean $\pm S D,{ }^{a} n=100,{ }^{b} n=30,{ }^{c} n=3$
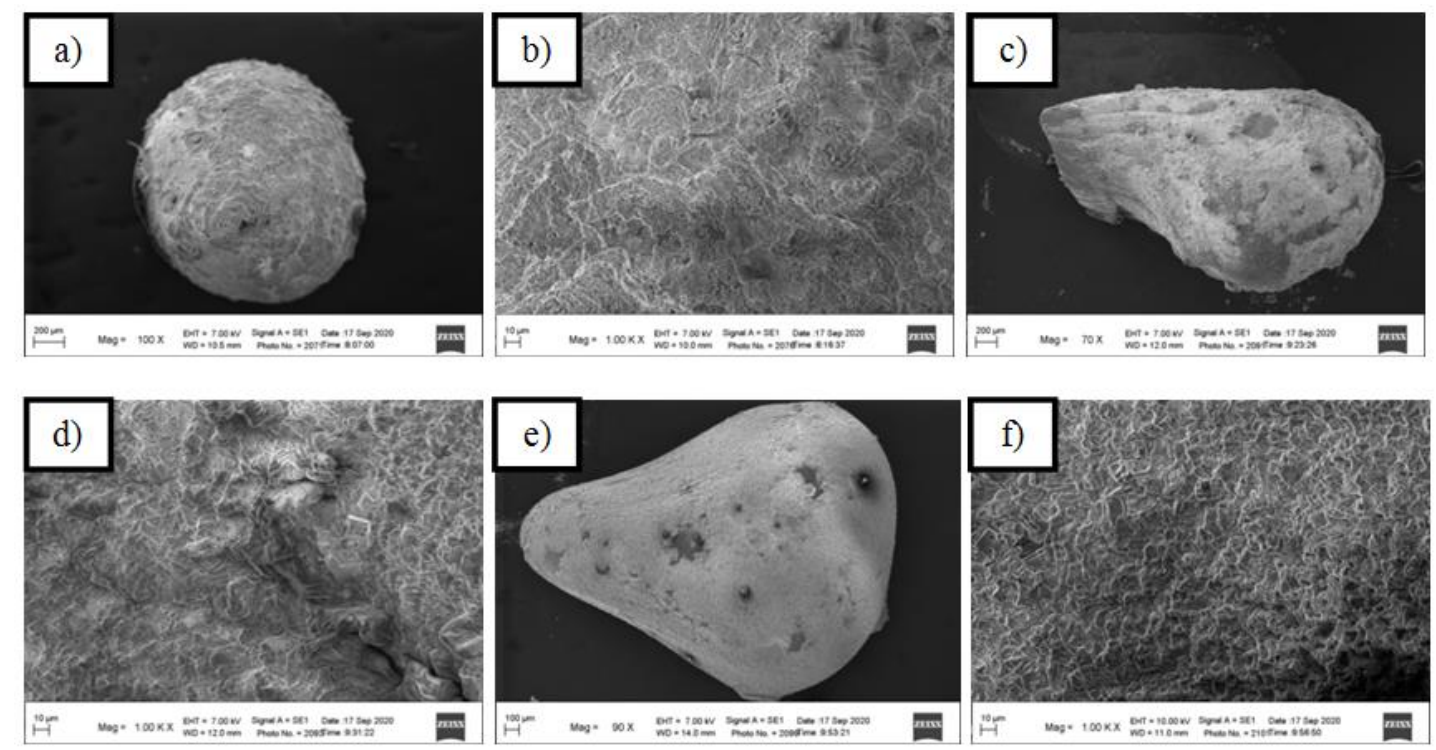

Fig. 2: SEM micrographs of a) bromelain-loaded alginate beads with magnification $100 \times$ b) $1000 \times$; c) bromelain-loaded pectin beads with magnification $70 \times$, d) $1000 \times$; e) bromelain-loaded AP beads with magnification $90 \times$, f) $1000 \times$

\section{Thermal analysis of bromelain-loaded beads}

Fig. 3 shows thermograms of bromelain, bromelain-loaded alginate, pectin, and AP complex beads. The endothermic peak appears at $128.69{ }^{\circ} \mathrm{C}$ for bromelain and $182.49{ }^{\circ} \mathrm{C}$ for pectin. While at the
178.16 and $296.26{ }^{\circ} \mathrm{C}$ assign as endothermic and exothermic peaks for alginate, respectively. A slight difference in AP occurs that endothermic and exothermic peaks appear at 188.93 and $297.36^{\circ} \mathrm{C}$. The bromelain peak was absent in biopolymer thermograms which confirms the complete entrapment of the bromelain [14].

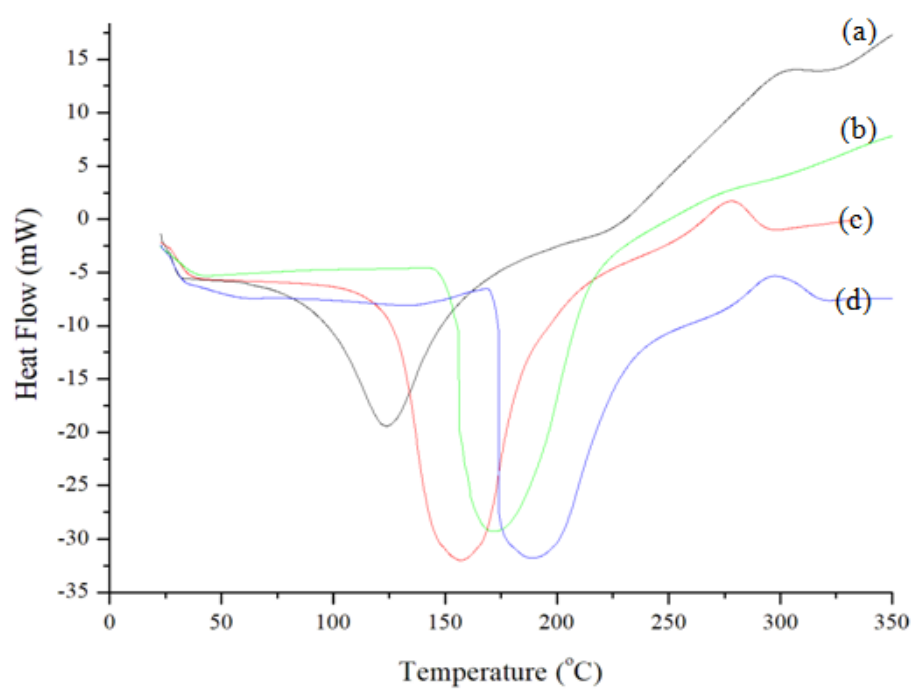

Fig. 3: DSC thermogram of a) bromelain, b) bromelain-loaded pectin, c) bromelain-loaded alginate, and d) bromelain-loaded AP beads 


\section{Determination of the swelling ratio}

In the swelling medium $0.1 \mathrm{~N} \mathrm{HCl}$, the $\mathrm{pH}$ medium below to $\mathrm{pKa}$ of alginate (3.38-3.65) [21] and pectin (3.5-4.5) [22], the carboxylic acid of alginate and pectin chain is in the non-ionized form $(-\mathrm{COOH})$ so that the structure of the beads is insoluble in the medium. The swelling properties of the beads are relatively low in an acidic medium. The phosphate buffer medium has a pH of 6.8, which higher than its pKa. In that condition, the alginate and pectin structures have an ionized form ( $\left.\mathrm{COO}^{-}\right)$so that there are repulsion forces between molecules with the same ionic charge [23]. The higher the amount of pectin, the higher the swelling ratios of the beads (fig. 4).

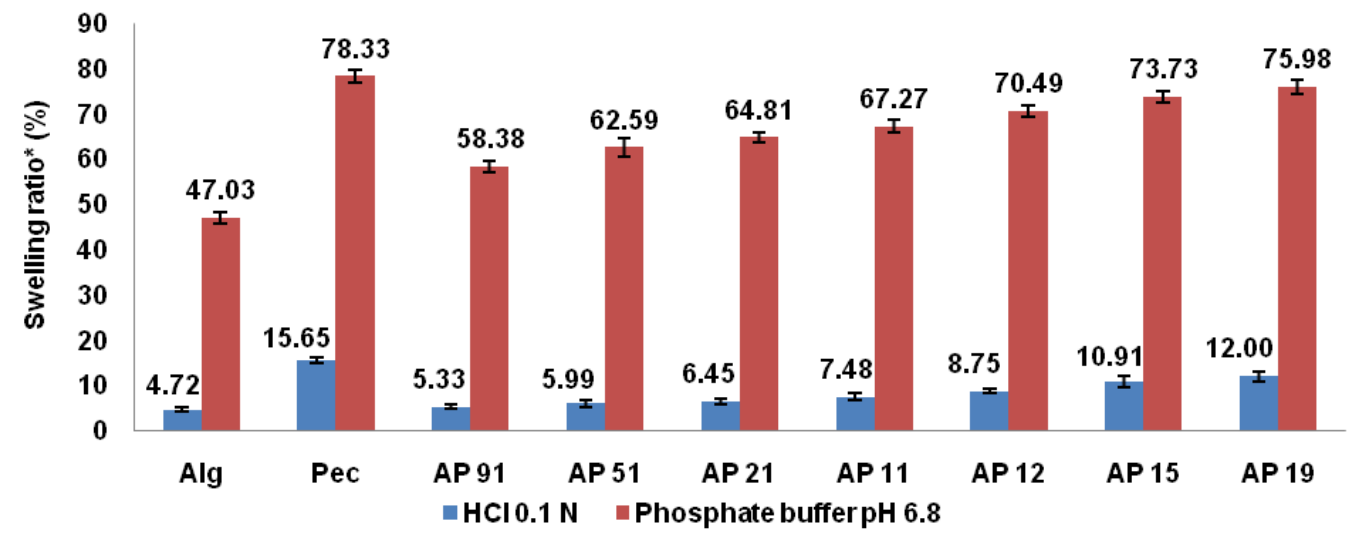

Fig. 4: Swelling ratios of various polymer composition beads. *Data represented as mean $\pm S D(n=3)$

\section{Encapsulation efficiency, dissolution profile, and kinetics study}

Table 2 shows that the encapsulation efficiency of bromelain in beads was increased as the amount of pectin increased. While fig. 1 shows that there is no interaction between bromelain and biopolymer of beads. There is no difference in terms of peaks on the FTIR spectrum before and after encapsulation; the interaction is in the hydrogen bond only [14].

The formula of beads used for in vitro dissolution was chosen considering encapsulation efficiency and swelling ratios in the medium. Pectin and AP 19 were chosen for in vitro dissolution based on that data. The profile of the in vitro dissolution data is shown in fig. 5 . The bromelain release in the $0.1 \mathrm{~N} \mathrm{HCl}$ medium was higher in pectin than in AP19. The dissolution in the phosphate buffer medium ( $\mathrm{pH}$ 6.8) of pectin was also higher than in AP19. Kinetics data shows that pectin and AP19 dissolution kinetics follows zeroorder models with a non-Fickian mechanism of release. The nonFickian transport means that the release processes occur through a combination of diffusion and erosion of the matrix beads. In the 0.1
$\mathrm{N} \mathrm{HCl}$ medium, the release of AP19 is more controlled until it moves into the phosphate buffer medium.

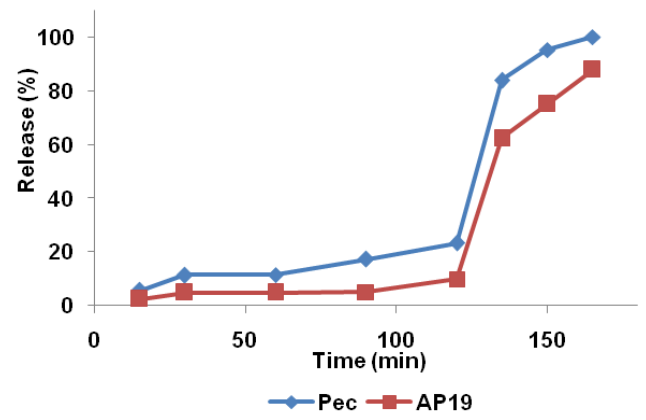

Fig. 5: The dissolution profile of bromelain from pectin and AP19

Table 3: Kinetics model fitting of in vitro bromelain release studies

\begin{tabular}{|c|c|c|c|c|c|c|}
\hline \multirow[t]{3}{*}{ Beads } & \multirow[t]{3}{*}{ Parameter } & \multicolumn{5}{|l|}{ Models } \\
\hline & & \multicolumn{3}{|c|}{ Dissolution kinetics } & \multicolumn{2}{|c|}{ Dissolution mechanism } \\
\hline & & Zero-order & First-order & Higuchi & Korsme & \\
\hline \multirow[t]{3}{*}{ Pectin } & $\mathrm{R}^{2}$ & 0.7659 & 0.6433 & 0.6737 & 0.9165 & Non-Fickian \\
\hline & $\mathrm{K}$ & 0.6483 & 0.0244 & 10.358 & 1.1860 & \\
\hline & $\mathrm{n}$ & - & - & - & 0.6034 & $0.43<\mathrm{n}<0.89$ \\
\hline \multirow[t]{3}{*}{ AP19 } & $\mathrm{R}^{2}$ & 0.7095 & 0.6479 & 0.6061 & 0.7745 & Non-Fickian \\
\hline & $\mathrm{K}$ & 0.5459 & 0.0115 & 8.5947 & 0.6554 & \\
\hline & $\mathrm{n}$ & - & - & - & 0.5192 & $0.43<\mathrm{n}<0.89$ \\
\hline
\end{tabular}

\section{In vitro antiplatelet activity}

This method compares the decrease of plasma solution absorbance given the presence of the sample before and after the addition of the aggregator compound. When the aggregator was added to the system, the platelet will create some aggregates and suspend them so that the absorbance was decreased. Significant decreases of absorbance are related to its worst activity as an antiplatelet agent. In this research, the percentage of aggregation from the negative control is considered a reference for determining antiplatelet activity. Based on fig. 6, in vitro antiplatelet activity of dialysis fraction is the highest $(56.04 \%)$ than other bromelain fraction, but still lower than cilostazol (98.05\%) and aspirin (96.76\%) as a commercial drug. The aliquot fractions of the dissolution process still show in vitro antiplatelet activity, although not at the same level as the dialysis fraction.

This result trend is in line with the previous study [12]. The mechanism of aspirin as an antiplatelet prodrug is by inhibiting the cyclooxygenase I (COX-I), which plays a role in converting arachidonic acid to prostaglandin $\mathrm{H} 2$ (PGH2). Also, $\mathrm{PGH} 2$ will further change into thromboxane A2 (TXA2) by using the thrombokinase enzyme to activate other platelets and promote the aggregation process. Meanwhile, cilostazol inhibits phosphodiesterase 3 , which has a function to convert cyclic adenosine monophosphate (cAMP) to adenosine monophosphate 
(AMP). This reduction in conversion results in inhibition of platelet activation and smooth muscle cell relaxation [24]. The mechanism of bromelain as an antiplatelet agent correlates with its proteolytic activity. Besides, based on other in vitro studies, bromelain is known to prevent thrombin-induced platelet aggregation and prevent platelet adhesion to endothelial cells [25].

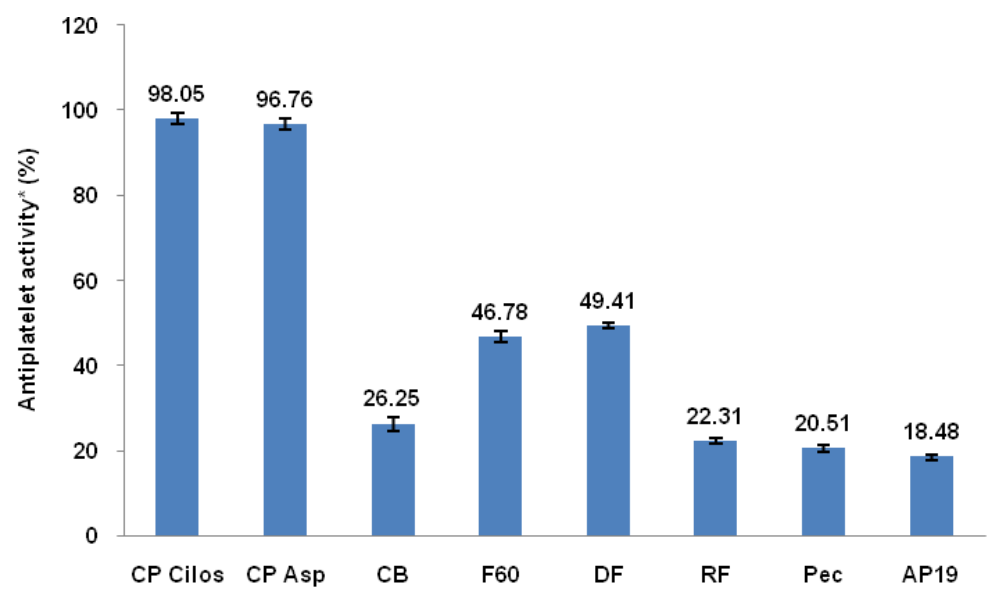

Fig. 6: Antiplatelet activity of each purification step and dissolution aliquots. *Data represented as $\operatorname{mean} \pm \operatorname{SD}(\mathrm{n}=3)$

\section{CONCLUSION}

The dialysis fraction has the highest specific activity of bromelain fraction compared to others so that this fraction will use in the encapsulation study. The ideal bromelain carrier was formulated using various compositions of alginate and pectin to study their physical properties. Based on the swelling and encapsulation efficiency data, pectin and AP19 were chosen for in vitro release. The kinetics data showed that the bromelain in both beads followed either a zero-order model with a non-Fickian release mechanism or a combination of diffusion and erosion. The aliquots of the dissolution process still showed antiplatelet activity in vitro.

\section{ACKNOWLEDGMENT}

This research was financially supported by the Pendidikan Magister Doktor untuk Sarjana Unggul (PMDSU) 2020 Program from the Ministry of Research and Technology/National Research and Innovation Agency Republic of Indonesia (contract number NKB3149/UN2. RST/HKP.05.00/2020).

\section{AUTHORS CONTRIBUTIONS}

Prof. Sumi Hudiyono and Dr. Emil Budianto, the guarantor of this study, designed and supervised the experimental process. Mr. Hegi Adi Prabowo carried out the experiments, analyzed the results, and contributed to the preparations and revisions of the manuscript.

\section{CONFLICTS OF INTERESTS}

The authors declare that there were no conflicts of interest.

\section{REFERENCES}

1. Ruan Y, Guo Y, Zheng Y, Huang Z, Sun S, Kowal P, et al. Cardiovascular disease (CVD) and associated risk factors among older adults in six low-and middle-income countries: results from SAGE wave 1. BMC Public Health 2018;18:778.

2. Alanon ME, Palomo I, Rodriguez L, Fuentes E, Arraez Roman D, Segura Carretero A. Antiplatelet activity of natural bioactive extracts from mango (Mangifera Indica L.) and its byproducts. Antioxidants 2019;8:517.

3. Badimon L, Vilahur G. Coronary atherothrombotic disease: progress in antiplatelet therapy. Rev Esp Cardiol 2008;5:501-13.

4. Geisler T, Anders N, Paterok M, Langer H, Stellos K, Lindemann $\mathrm{S}$, et al. Platelet response to clopidogrel is attenuated in diabetic patients undergoing coronary stent implantation. Diabetes Care 2007;30:372-4.

5. Kong Y, Xu C, He ZL, Zhou QM, Wang JB, Li ZY, et al. A novel peptide inhibitor of platelet aggregation from stiff silkworm, Bombyx batryticatus. Peptides 2014;53:70-8.
6. Brites MM, Ceron AA, Costa SM, Oliveira RC, Ferraz HG, Catalani LH, et al. Bromelain immobilization in cellulose triacetate nanofiber membranes from sugarcane bagasse by electrospinning technique. Enzyme Microb Technol 2020;132:109384.

7. Setiasih S, Prabowo HA, Budianto E, Hudiyono S. Dissolution profiles of partially purified bromelain from pineapple cores [Ananas comosus (L.) merr] encapsulated in glutaraldehydecrosslinked chitosan. J Appl Pharm Sci 2018;8:17-24.

8. Setiasih S, Darwis AAC, Dzikria V, Hudiyono S. Stability test of partially purified bromelain from pineapple (Ananas comosus (L.) merr) core extract in artificial stomach fluid. IOP Conf Ser: Mater Sci Eng 2018;299:1-7.

9. Chobotova K, Vernallis AB, Majid FAA. Bromelain's activity and potential as an anti-cancer agent: current evidence and perspectives. Cancer Lett 2010;290:148-56.

10. Auriemma G, Mencherini T, Russo P, Stigliani M, Aquino RP, Gaudio PD. Prilling for the development of multi-particulate colon drug delivery system: pectin vs pectin-alginate beads. Carbohydr Polym 2013;92:367-73.

11. Chung YS, Park J, Noh J, Chang ST, Kim JS, Kim J. Microencapsulation by pectin for multi-components carriers bearing both hydrophobic and hydrophilic active agents. Carbohydr Polym 2017;182:172-9.

12. Irfan AA, Setiasih S, Hudiyono S. Dissolution profile of partially purified bromelain from pineapple core encapsulated in alginate-guar gum with in vitro study of antiplatelet activity. IOP Conf Ser: Mat Sci Eng 2020;763:0102042.

13. Richards C, Oconnor N, Jose D, Barret A, Regan F. Selection and optimization of protein and carbohydrate assays for the characterization of marine biofouling. Anal Methods 2020;12:2228-36.

14. Sinha P, Udhumansha U, Rathnam G, Ganesh M, Jang HT. Capecitabine encapsulated chitosan succinate-sodium alginate macromolecular complex beads for colon cancer targeted delivery: in vitro evaluation. Int J Biol Macromol 2018;117:840-50.

15. Macdonald M, Rodriguez NM, Smith R, Hammond PT. Release of a model protein from biodegradable self-assembled films for surface delivery applications. J Controlled Release 2008;131:228-34.

16. Guo J, Miao Z, Wan J, Guo X. Pineapple peel bromelain extraction using gemini surfactant-based reverse micelle-Role of spacer of gemini surfactant. Sep Purif Technol 2018;190:156-64.

17. Bernela $M$, Ahuja $M$, Thakur R. Enhancement of antiinflammatory activity of bromelain by its encapsulation in katira gum nanoparticles. Carbohydr Polym 2016;143:18-24.

18. Devi P, Rathor S, Sharma P, Sen J, Kaur H, Singh J. Development of novel gastroretentive salbutamol sulfate-loaded sodium alginate-pectin bubble beads prepared by co-axial needle air- 
injection method and in vivo clinical evaluation by ultrasound studies. Eur J Pharm Sci 2018;122:359-73.

19. Nesic A, Onjia A, Davidovic S, Dimitrijevic S, Errico ME, Santagata $G$, et al. Design of pectin-sodium alginate-based films for potential healthcare application: study of chemico-physical interactions between the components of films and assessment of their antimicrobial activity. Carbohydr Polym 2017; 157:981-90.

20. Voo WP, Lee BB, Idris A, Islam A, Tey BT, Chan ES. Production of ultra-high concentration calcium alginate beads with prolonged dissolution profile. RSC Adv 2015;5:36687-95.

21. Abasalizadeh F, Moghaddam SV, Alizadeh E, Akbari E, Kashani E, Fazljou SMB, et al. alginate-based hydrogels as drug delivery vehicles in cancer treatment and their applications in wound dressing and 3D bioprinting. J Biol Eng 2020;14:8.
22. Gawkowska D, Cybulska J, Zdunek A. Structure-related gelling of pectins and linking with other natural compounds: a review. Polymers 2018;10:762.

23. Ganesh D, Suresh P, Rao GS. Fabrication of sodium alginate/gum ghatti IPN microbeads intercalated with kaolin nano clay for controlled release of curcumin. Int J Appl Pharm 2021;13:223-41.

24. Eikelboom JW, Hirsh J, Spencer FA, Baglin TP, Weitz JI. Antiplatelet drugs: antithrombotic therapy and prevention of thrombosis. 9th ed: American college of chest physicians evidence-based clinical practice guidelines. Chest 2012;141(2 Suppl):e89S-e119S

25. Metzig C, Grabowska E, Eckert K, Rehse K, Maurer HR. Bromelain proteases reduce human platelet aggregation in vitro, adhesion to bovine endothelial cells and thrombus formation in rat vessels in vivo. In Vivo 1999;13:7-12. 